\title{
TEM Investigation on the Relationship Between Catalytic Activity and Structure in $\mathrm{Rh} / \mathrm{Al}_{2} \mathrm{O}_{3}$ Catalysts
}

\author{
Cheng-Han $\mathrm{Li}^{1}$, Jason $\mathrm{Wu}^{2}$, Chris Chae ${ }^{1}$, and Joerg R. Jinschek ${ }^{1 *}$ \\ 1. The Ohio State University, Columbus, OH, USA \\ 2. Research and Innovation Center, Ford Motor Company, Dearborn, MI, USA \\ * Corresponding author: jinschek.1@osu.edu
}

Supported noble metal catalysts, such as Platinum (Pt), Palladium (Pd) and Rhodium (Rh), are widely used as three-way catalysts (TWCs) in automotive industry to reduce the emission of exhaust gases. In particular, $\mathrm{Rh}$ is the most favorable choice over Pt and Pd due to the activity of $\mathrm{Rh}$ under both lean (above stoichiometric air-fuel ratio) and rich (below stoichiometric air-fuel ratio) conditions in addition to a low production of undesired $\mathrm{NH}_{3}$ [1]. However, Rh-based catalysts exhibit deactivation phenomenon at elevated temperatures due to strong interactions with the support, here alumina $\left(\mathrm{Al}_{2} \mathrm{O}_{3}\right)$, for a variety of reasons [2-7], such as diffusion into supports [2,3] and particle growth [4]. The ambiguity in understanding $\mathrm{Rh}$ deactivation at elevated temperatures is due to the lack of direct atomic-scale observation of the interaction between Rh metal particles and the oxide support surface. In this study, the effects of morphology changes of actual $\mathrm{Rh} / \mathrm{Al}_{2} \mathrm{O}_{3}$ automotive catalysts and the metal-support interactions on the catalytic activity under alternating lean and rich conditions are investigated using scanning transmission electron microscopy (STEM) and electron energy loss spectroscopy (EELS).

$\mathrm{Rh} / \mathrm{Al}_{2} \mathrm{O}_{3}(5 \mathrm{wt} \%)$ catalysts were prepared using incipient wetness impregnation and were calcined at $600^{\circ} \mathrm{C}$ followed by reduction in $\mathrm{H}_{2}$ environment at $450^{\circ} \mathrm{C}$. Subsequent oxidation in $\mathrm{O}_{2}$ environment above $900^{\circ} \mathrm{C}$ and further regeneration reduced in $\mathrm{H}_{2}$ at $850^{\circ} \mathrm{C}$ were done to study the oxidation and regeneration effect in comparison with pulsator-aged catalysts. The activity of the catalysts was examined by light-off tests with a typical three-way catalyst feed mixture. $\mathrm{Rh} / \mathrm{Al}_{2} \mathrm{O}_{3}$ powder was tested in a plug-flow reactor and the activity was determined based on the temperature at which $50 \%$ conversions of $\mathrm{CO}_{2} \mathrm{C}_{3} \mathrm{H}_{6}$, and NO is achieved. TEM specimens were prepared by crashing the treated catalysts powders and dispersing in ethanol and dropping onto a copper TEM grid with lacey carbon films. The high-resolution high-angle annular dark-field (HAADF) STEM images were carried out using a Titan 60-300 S/TEM. EEL spectra were collected using a Gatan Image Filter (GIF) Quantum ERS system with the energy resolution of $1 \mathrm{eV}$. The particle size distribution measurements have been carried out on at least 50 individual particles.

Figure 1a shows high-resolution STEM image of an individual Rh particle. Figure 1b\&c show HAADF STEM images of freshly reduced catalyst with $\mathrm{Rh}$-metal particles evenly distributed on the $\mathrm{Al}_{2} \mathrm{O}_{3}$ support with an average particle size of $1.6 \mathrm{~nm} \pm 0.5 \mathrm{~nm}$. After oxidation at $950^{\circ} \mathrm{C}$, the catalyst is now composed of $\mathrm{Rh}$ atom clusters with an average size of $0.6 \mathrm{~nm} \pm 0.2 \mathrm{~nm}$ (as indicated by arrows in Figure 1d) and sintered Rh particles with particle size of $12.5 \mathrm{~nm} \pm 3.3 \mathrm{~nm}$ (Figure 1e). As shown in Figure 1f\&g, further reduction at $850^{\circ} \mathrm{C}$ leads to the reappearance of the $\mathrm{Rh}$ particles with an average particle size of $1.7 \mathrm{~nm} \pm$ $0.3 \mathrm{~nm}$ and the coexistence of larger coalesced $\mathrm{Rh}$ particles $(22.1 \mathrm{~nm} \pm 8.2 \mathrm{~nm})$. In Figure 2, a series of EEL spectra taken across the sintered Rh particles shows the variation in the local chemistry. The Rh $\mathrm{M}_{2}$ peak accompanying with the split of oxygen $\mathrm{K}$ edge suggests the change of local bonding environments of $\mathrm{Rh}$ as well as of oxygen. The split of $\mathrm{O} \mathrm{K}$ edge is believed to be a pre-edge peak from a metal oxide exhibiting varying oxidation states. This indicates that, after treatment under oxidizing conditions, the $\mathrm{Rh}$ nanoparticles not only sinter into larger particles but also form rhodium oxide. Based on the temperature at which $50 \%$ conversion is achieved, the second reduction step at $850^{\circ} \mathrm{C}$ reverses the previously observed 
catalysts deactivation and restores the activity. This ability to restore catalytic activity when used in an automotive catalytic converter application makes Rh-based catalysts more competitive compared to the established Pt- and Pd-based catalysts that are more susceptible to the sintering effect and thus the loss in catalytic activity in working conditions [8].

References:

[1] M Shelef and R. W. McCabe, Catal. Today, 62 (2000), p. 35.

[2] HC Yao, HK Stepien, and HS Gandhi, J. Catal., 61 (1980), p. 547.

[3] JG Chen et al., J. Phys. Chem., 94 (1990), p. 5059.

[4] HC Yao, S Japar, and M Shelef, J. Catal., 50 (1977), p. 407.

[5] C Wong and RW McCabe, J. Catal., 1191 (1989), p. 47.

[6] DD Beck et al., J. Catal., 144 (1993), p. 311.

[7] RW McCabe et al., J. Catal., 151 (1995), p. 385.

[8] The authors acknowledge the funding and experimental supports from Ford Motor Company.

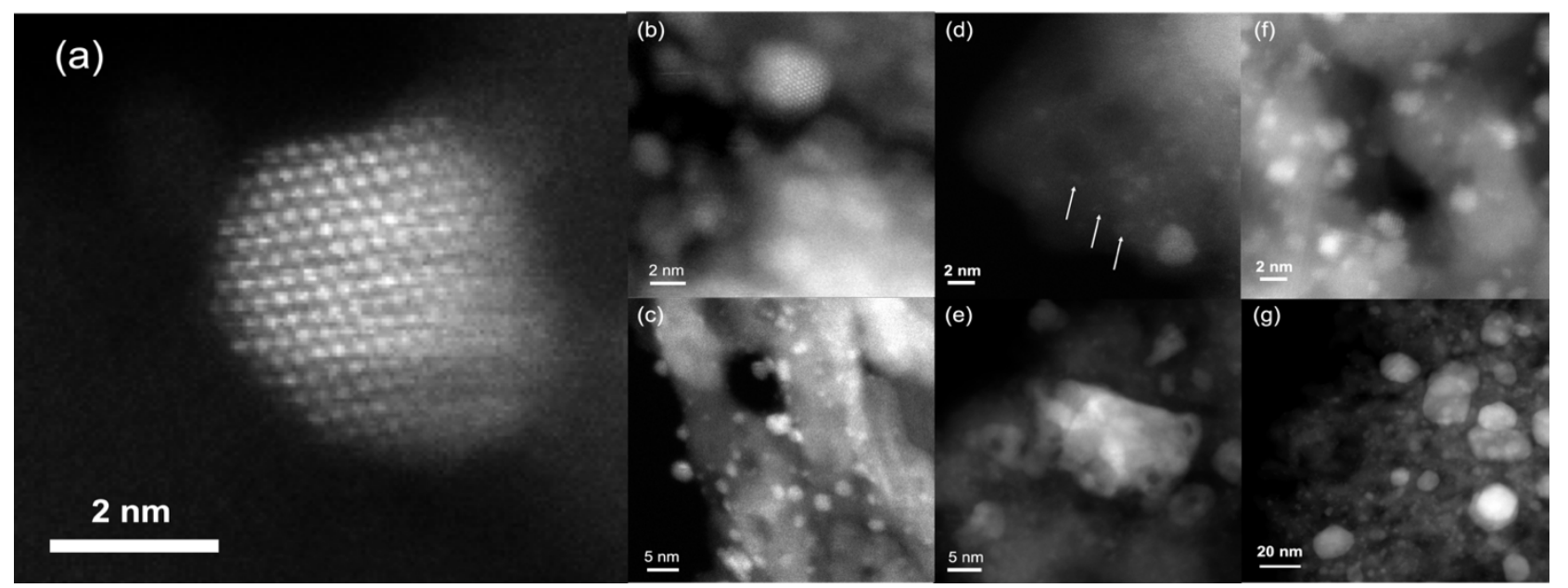

Figure 1. High-angle annular dark-field (HAADF) STEM images of 5 wt. $\% \mathrm{Rh} / \mathrm{Al}_{2} \mathrm{O}_{3}$. (a) high-resolution HAADF STEM image of Rh particle, $(b, c)$ under reducing conditions at $450^{\circ} \mathrm{C}$, $(\mathrm{d}, \mathrm{e})$ subsequent oxidation at $950{ }^{\circ} \mathrm{C}$, and (f, g) reductive regeneration at $850{ }^{\circ} \mathrm{C}$. The arrows in (d) indicate the $\mathrm{Rh}$ atom clusters embedded in the support.
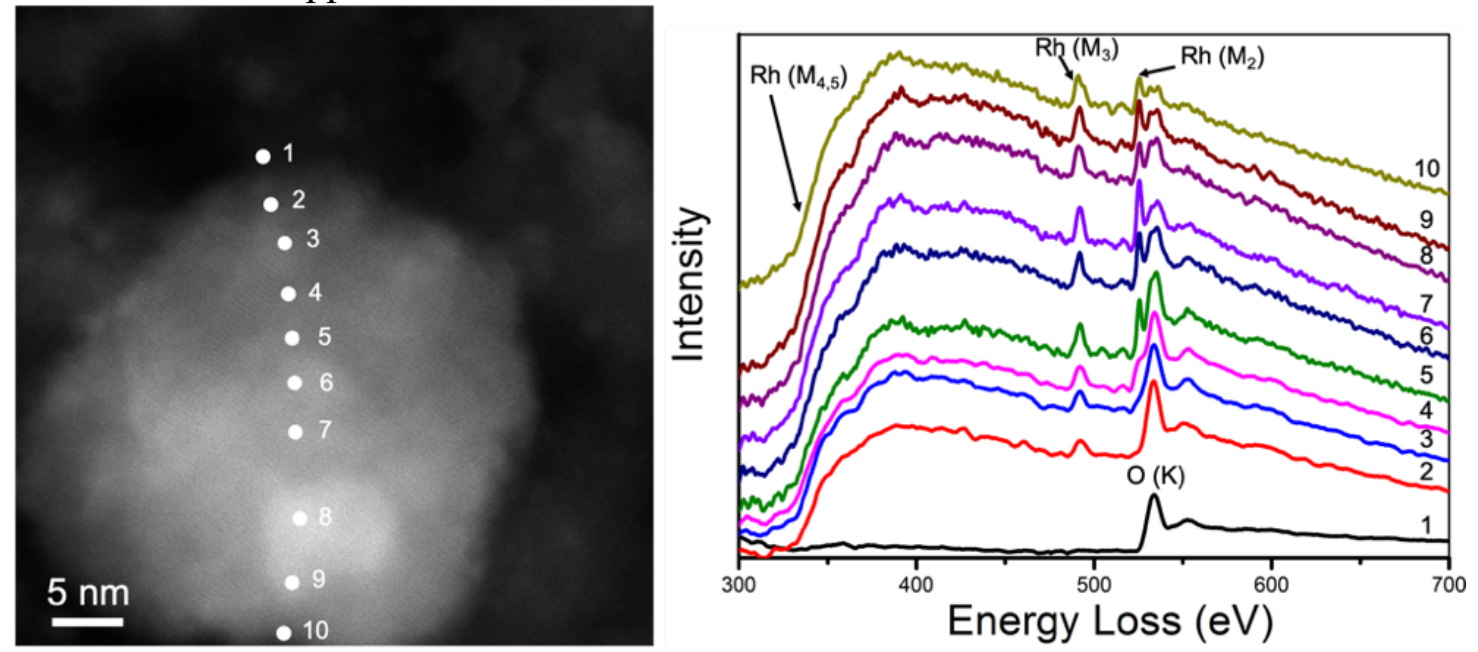

Figure 2. HAADF STEM image of oxidized $\mathrm{Rh} / \mathrm{Al}_{2} \mathrm{O}_{3}$ catalysts with EEL spectra of the core structure in the region of $300 \mathrm{eV}$ to $700 \mathrm{eV}$ from ten individual positions across a sintered $\mathrm{Rh}$ particle. 